Res., Soc. Dev. 2019; 8(9):e45891328

ISSN 2525-3409 | DOI: http://dx.doi.org/10.33448/rsd-v8i9.1328

\title{
A Terraformação de Marte como tema interdisciplinar para abordar conhecimento
} científico no ensino médio

The Terraforming of Mars as an interdisciplinary subject to approach scientific knowledge in High School

La Terraformación de Marte como tema interdisciplinario para abordar el conocimiento científico en la enseñanza media

Recebido: 20/06/2019 | Revisado: 21/06/2019 |Aceito: 26/06/2019 | Publicado: 27/06/2019

Afonso Werner da Rosa

ORCID: https://orcid.org/0000-0002-3848-5598

Universidade de Passo Fundo, Brasil

E-mail: afonsowr@hotmail.com

Alisson Cristian Giacomelli

ORCID: https://orcid.org/0000-0002-8490-4132

Universidade de Passo Fundo, Brasil

E-mail: alissongiacomelli@upf.br

Álvaro Becker da Rosa

ORCID: https://orcid.org/0000-0001-9713-8054

Universidade de Passo Fundo, Brasil

E-mail: alvaro@upf.br

\section{Resumo}

O texto apresentado tem por objetivo apresentar uma proposta de atividades didáticas de natureza interdisciplinar para o ensino médio, tendo como eixo norteador a utilização de um tema instigante, no caso a Terrafomação de Marte. O estudo parte da discussão de interdisciplinaridade e na sequência apresenta uma pesquisa bibliográfica que possibilitou formular a proposta didática, aspecto central do texto. A proposta didática é pautada por questionamentos e discussões entorno da possibilidade de criar em Marte as condições de vida existente na Terra e, assim habitar esse planeta: Podemos terraformar Marte? O que é necessário para isso? Como seria a adaptação da vida em Marte? A partir dessas perguntas, são indicadas discussões referentes a tópicos interdisciplinares que podem ser abordados em aula. O estudo finaliza apontando a validade deste tipo de atividade, particularmente quando se trata de temas de interesse dos alunos e, ainda, ressalta que uma disciplina específica não 
daria conta de responder tais questionamentos, o que referenda a necessidade de um ensino interdisciplinar.

Palavras-chave: Interdisciplinaridade; Proposta didática; tema instigador.

\begin{abstract}
The present text aims to present a proposal of didactic activities of an interdisciplinary nature for high school, having as its guiding principle the use of an exciting topic, in the case of terraforming de Marte. The research starts from the discussion of interdisciplinarity and as a result presents a bibliography study that made possible to form the didactic proposal, which is the main aspect of the text. The didactic proposal is guided by questionings and debates around the possibility of creating in Mars the life conditions of Earth, so it's possible to live in the planet: Can we terraform Mars? What is necessary for that? How would the adjustment of life be in Mars? From these questions, discussions referring to interdisciplinary topics that can be approached in the classroom are indicated. The essay ends pointing out the validity of this kind of activity, especially when it's about themes of the students' interests, and it emphasizes that a specific discipline would be able to answer these questions, which acknowledge the necessity of interdisciplinary education.
\end{abstract}

Keywords: Interdisciplinary; Didactic proposal; instigating theme.

\title{
Resumen
}

El texto presentado tiene por objetivo presentar una propuesta de actividades didácticas de naturaleza interdisciplinaria para la enseñanza media, teniendo como eje orientador la utilización de un tema instigador, en el caso la Tierrafomación de Marte. El estudio parte de la discusión de interdisciplinaridad y en la secuencia presenta una investigación bibliográfica que posibilitó formular la propuesta didáctica, aspecto central del texto. La propuesta didáctica es pautada por cuestionamientos y discusiones en torno a la posibilidad de crear en Marte las condiciones de vida existentes en la Tierra y, así habitar ese planeta: ¿Podemos terraformar a Marte? ¿Qué es necesario para ello? ¿Cómo sería la adaptación de la vida en Marte? A partir de estas preguntas, se indican discusiones sobre temas interdisciplinarios que pueden abordarse en clase. El estudio finaliza apuntando la validez de este tipo de actividad, particularmente cuando se trata de temas de interés de los alumnos y, aún, resalta que una disciplina específica no daría cuenta de responder tales cuestionamientos, lo que refrenda la necesidad de una enseñanza interdisciplinaria.

Palabras clave: Interdisciplinaridad; Propuesta didáctica; tema instigador.

\section{Introdução}

A elaboração de propostas didáticas interdisciplinares representa um desafio para os 
professores que, frente a uma formação disciplinar, precisam buscar alternativas para estruturar práticas pedagógicas e contemplar temas interdisciplinares. As pesquisas educacionais têm discutido essa problemática evidenciando a necessidade de contempla a interdisciplinaridade em sala de aula, superando a visão tradicionalmente presente na educação básica de que cada disciplina tem um copo de conhecimentos isolado e desconectados dos demais (Hartmann, \& Zimmermann, 2007; Mozema, \& Ostermann, 2016).

Desde a promulgação dos Parâmetros Curriculares Nacionais (PCNs) no final dos anos de 1990 e persistindo até a recente divulgação da Base Nacional Curricular Comum (BNCC), o tema interdisciplinaridade tem sido abordado e enfatizado no cenário nacional, revelando-se um caminho sem retorno, do qual os professores precisam dedicar parte de suas atividades pedagógicas. Nesse sentido, Ricardo (2005) mostra as divergências de compreensão existentes entorno do conceito de interdisciplinaridade, especialmente em relação ao exposto nos Parâmetros Curriculares Nacionais (PCNs). Para o autor o documento foi elaborado por especialistas que não mantém um consenso sobre o entendimento, apresentando distintas concepções sobre o seu sentido.

No campo das pesquisas nacionais, a temática tem instigado debates e discussões, particularmente vinculadas a reflexões e referenciais teóricos que possibilitam a compreensão das bases filosóficas e pedagógicas da interdisciplinaridade. Todavia, poucas são as pesquisas que se ocupam de apesenta alternativas que apontem ações possíveis de serem implementadas em sala de aula. Ou como discutido por Hartmann e Zimmermann (2007) e Rosa, Darroz e Rosa (2014), sua efetivação no contexto escolar ainda carece de mais discussões e, especialmente, de propostas didáticas que possam subsidiar a ação dos professores.

Somado a isso, temos a necessidade de que o contexto educativo se torne mais atrativo para os alunos, contribuindo para qualificação do processo de aprendizagem. Nesse contexto, partimos da importância de trazer assuntos em discussão na mídia e fomentar debates em sala de aula de modo a envolver as diferentes disciplinas curriculares. Abordar temas instigantes como os vinculados a Astronomia, por exemplo, tem se mostrado propício para estabelece debates e promove a curiosidade dos alunos como apontado por Silva (2019). No estudo, o autor recorre ao calendário cósmico para abordar tópicos de Astronomia e infere ao final do estudo que ao contextualizar o conhecimento recorrendo a temas instigantes, promove a formulação de perguntas e o engajamento dos estudantes.

Tais entendimentos frente a necessidade de contemplar propostas didáticas interdisciplinares e a necessidade de trazer para esse contexto temas instigantes e de interesse dos estudantes, subsidiou a proposta didática apresentada neste trabalho e está pautada por um 
ensino motivador e comprometido com a formação crítica e plena dos sujeitos. O proposto considera a necessidade de iniciar pela apresentação de um questionamento e levar aos estudantes possibilidades de temas que desejam discutir. Um dos temas que pode ser de interesse é sobre a terraformação de Marte. A possibilidade hipotética de que poderíamos criar em Marte as condições de vida existente na Terra e assim habitarmos esse planeta, é provocador de discussões envolvendo diferentes áreas do conhecimento, como deve ser um tema interdisciplinar. Partiremos dele para discutir a proposta de atividades interdisciplinares a que esse texto se ocupa.

Desta forma, temos como objetivo apresentar uma proposta de atividades didáticas de natureza interdisciplinar para o ensino médio, tendo como eixo norteador a utilização de um tema instigante, no caso a Terrafomação de Marte. Para isso recorremos a uma investigação bibliográfica buscando o embasamento teórico na interdisciplinaridade para, a partir dessa compreensão propor uma atividade no campo das Ciências presentes no ensino médio, sobre a possibilidade dessa Terraformação de Mate.

\section{Interdisciplinaridade no ensino}

A história nos mostra uma tradição de ensino pautado por disciplinas, cujas recomendações educacionais apontam para a necessidade de implementar práticas pedagógicas interdisciplinares. Todavia, temos que ter em mente que a presença das disciplinas, particularmente as que integram a área das ciências naturais como Física, Química e Biologia tem uma história de aproximadamente trezentos anos. You (2017) mostra que até o Renascimento, o sistema de classificação de disciplinas não existia, e uma variedade de conhecimentos foi integrada sob um guarda-chuva chamado "filosofia natural". A partir do século XVIII, a crescente especialização e profissionalização da ciência deu origem a novas disciplinas acadêmicas e possibilitou uma maneira poderosa de organizar o conhecimento considerando à quantidade excessiva de conhecimento científico produzido na época. Além disso, Stichweh (2003) chama a atenção que a disciplinaridade está relacionada com as limitações cognitivas dos seres humanos que apresentam mais facilidade para manusear o conhecimento de forma separada, em disciplinas específicas. A crescente especialização da ciência foi ainda mais acelerada pelo predomínio do reducionismo até a primeira metade do século XX.

You (2017) ressalta que, embora a ciência tenha se desenvolvido por séculos com uma estrutura baseada em disciplina dominante, sempre houve a necessidade de superar as 
Res., Soc. Dev. 2019; 8(9):e45891328

ISSN 2525-3409 | DOI: http://dx.doi.org/10.33448/rsd-v8i9.1328

fronteiras fechadas de disciplinas científicas. No início dos anos 1930, a "unidade do movimento científico" foi iniciada por cientistas naturais e filósofos da ciência que argumentavam que o conhecimento tem perspectivas mais variadas e multifacetadas do que a rigorosa classificação e compartimentalização de disciplinas específicas. Continua o autor, mencionado Hurd (1991), que esse movimento levou à afirmação de que uma abordagem vinculada à disciplina não é mais a estrutura crucial para o delineamento do conhecimento.

A partir dessa visão e somado ao descontentamento de estudantes sobre o ensino disciplinar e fragmentado das disciplinas universitárias, na década de 1960 inicia um movimento na França e que depois se estende aos demais países que busca estabelecer uma conexão entre os conhecimentos discutindo, iniciando um resgate pela interdisciplinaridade.

Dentre os representantes nacionais que iniciaram os estudos nessa área, voltando-se a identificar as bases epistemológicas que sustentam a importância da interdisciplinaridade, está Hilton Japiassu e Inani Fazenda. O entendimento desses autores tem permeados as práticas educativas e inferem a eles o caráter de referencial das discussões no campo da interdisciplinaridade na escola brasileira.

A interdisciplinaridade é assim expressa por Japiassu (1976, p. 75),

\begin{abstract}
Podemos dizer que nos reconhecemos diante de um empreendimento interdisciplinar todas as vezes em que ele conseguir incorporar os resultados de várias especialidades, que tomar de empréstimo a outras disciplinas certos instrumentos e técnicas metodológicos, fazendo uso dos esquemas conceituais e das análises que se encontram nos diversos ramos do saber, a fim de fazê-los integrarem e convergirem, depois de terem sido comparados e julgados. Donde podermos dizer que o papel específico da atividade interdisciplinar consiste, primordialmente, em lançar uma ponte para ligar as fronteiras que haviam sido estabelecidas anteriormente entre as disciplinas com o objetivo preciso de assegurar a cada uma seu caráter propriamente positivo, segundo modos particulares e com resultados específicos
\end{abstract}

Para Pineau e Le Grand (2002) a interdisciplinaridade resulta da inquietação dos pesquisadores, sendo potencializada pela necessidade estabelecida na compreensão de determinados paradoxos decorrentes da busca pelo sentido da existência humana. Seguem os autores relatando que isso está relacionado a critérios de funcionalidade necessários e sem os quais há quebra de princípios básicos de humanidade em seu sentido mais amplo significado.

No campo educacional, Japiassu (1976) mostra que a interdisciplinaridade exige que o professor repense sua ação pedagógica, reestruturando seu fazer e explorando novos domínios, de modo a apresentar novas competências e articulações entre os saberes. Nessa compreensão, o professor interdisciplinar precisa apresentar um conjunto de competências relacionadas aos domínios práticos e teóricos, possibilitando proporcionar a articulação entre 
ISSN 2525-3409 | DOI: http://dx.doi.org/10.33448/rsd-v8i9.1328

as diferentes disciplinas escolares. Ainda, segundo Japiassu (1992), a interdisciplinaridade corresponde a um novo desenvolvimento do conhecimento na qual as disciplinas acabam por fundir-se por meio de uma articulação constante, o que acarreta a adoção de métodos que se fundamentem mais no exercício de aptidões intelectuais e de faculdades psicológicas identificadas com a pesquisa do que necessariamente em informações armazenadas na memória.

Na perspectiva de Fazenda (1994) a interdisciplinaridade se revela como uma atitude frente a fragmentação do conhecimento. Em seu entender e exemplificando o mencionado, essa atitude se expressa por meio da habilidade que os professores têm para exercer trocas com seus pares, que são os especialistas disciplinares, com objetivo explícito de realizar trocas a fim de desenvolver um projeto interdisciplinar. Os professores devem exercer trocas não apenas entre seus conhecimentos e métodos, mas também entre suas experiências e visões de mundo. Além disso, a autora chama a atenção para o fato de que é a intensidade dessas trocas devem ter objetivos claros e fins definidos, proporcionando o enriquecimento mútuo. A interdisciplinaridade, não estaria limitada de modo singular ao conhecimento, mas a um movimento amplo de interação entre diversas possibilidades de conhecimento que as disciplinas são capazes de desdobrar (Fazenda, 1996).

Reportando-se ao campo educacional, a autora menciona que a interdisciplinaridade representa uma prática de integração, caracterizada "pela intensidade das trocas entre os especialistas e pelo grau de integração real das disciplinas no interior de um mesmo projeto de pesquisa" (1996, p. 25). Todavia, é preciso considerar que essas tricas são difíceis de serem concretizadas, uma vez que tanto os professores por sua formação e, algumas vezes, concepção, acabam limitando-se as suas disciplinas. Fazenda (1991) mostra a necessidade de que os professores revisem suas práticas pedagógicas como possibilidade de avanço em ações transformadoras, entretanto, não infere a forma como isso pode ocorrer, principalmente no ensino médio. Esse nível de escolarização é marcado por ações voltadas a apropriação dos conceitos e a praticas pedagógicas que permitam aos estudantes o acúmulo de conhecimento, linearizado, descontextualizado e desconectado dos demais. Dificilmente se percebe ações que valorizem a interação entre as disciplinas e que valorizem o caráter coletivo e interdisciplinar da produção do conhecimento.

Todavia, precisamos considerar a exemplos de autores especialista da área, que o ensino interdisciplinar é construído sobre o conhecimento de conteúdo bem estabelecido de cada ciência disciplinar, porque a especialização é um precursor da interdisciplinaridade. Como mostram Baumert et al. (2010), o conhecimento de conteúdo especializado é uma 
condição necessária e um pré-requisito para a aquisição de bases de conhecimento de outras disciplinas e para a provisão de ensino poderoso. Se os professores de ciências têm conhecimento insuficiente nos tópicos específicos da disciplina, eles também não terão a capacidade de integrar os conceitos. Talvez resida aí uma das dificuldades dos professores de ciências para desenvolver práticas pedagógicas interdisciplinares.

Frente a esse contexto da necessidade de uma abordagem interdisciplinar e ao mesmo tempo as dificuldades que se impõe a ela, apresentamos na continuidade uma proposta de atividades que tem por objetivo instigar os estudantes na busca pelo conhecimento, ao mesmo tempo que mostra esse caráter interdisciplinar dos saberes escolares.

\section{Proposta didática}

A presente seção se ocupa de apresentar uma possibilidade de abordar o tema em discussão a partir de uma proposta didática. Por proposta didática entendemos a organização sistematizada de ações a partir de um objetivo pedagógico e relacionada a um objetivo especifico (Rosa, 2001).

Persiste no imaginário coletivo a ideia um pouco romanceada de que seria possível colonizar e viver em outros planetas, bem como viajar entre lugares longínquos e até entre galáxias em tempos muito curtos. Os roteiros cinematográficos são de tal forma envolventes e elaborados que não suscitam dúvidas da possibilidade disso. Nestas obras de ficção, ao menos por enquanto, parece que não existem dificuldades de grande monta, e permanecemos presos as tramas dos personagens do enredo. Tudo que é apresentado são pequenas dificuldades sendo solucionadas de maneira ingênua.

A proposta desta atividade pode iniciar com o professor dividindo a turma entre 2 a 4 grupos e estabelecendo como tarefa para cada grupo assistir previamente a um filme diferente de ficção relativa ao tema de viagens espaciais e vida em outros planetas. Após assistir ao filme, o grupo deve elaborar a uma sinopse e apresentar aos colegas ressaltando tópicos interessantes: enredo e ambientação, habilidades e tecnologias utilizadas e/ou disponíveis para os personagens, as cidades e as sociedades, etc. Essa é uma atividade empolgante para os cinéfilos, e motiva um pouco até mesmo quem não é profundamente apaixonado pela sétima arte. Os filmes tocam as pessoas e despertam o imaginário e uma aula onde cada grupo possa narrar um filme de sua escolha pode ser instigante. Seja qual for o filme, haverá uma cena de combate, de sobrevivência ou simplesmente cotidiana qualquer que desperta críticas pela viabilidade ou não da tecnologia empregada. Muitos apaixonados pela ficção podem ficar 
envolvidos pela trama e relevar as impossibilidades assim como os mais céticos podem questionar a validade técnico científica do que é apresentado (Carvalho Piassi, 2013; Vidal, 2013).

Para reduzir a dispersão do grupo, um roteiro básico pode ser elaborado aos alunos com as informações prévias a serem levantadas ao assistir ao filme e sua posterior apresentação a classe para que possam se tornar temas geradores. Podem ser sugeridas perguntas abertas sobre o ambiente, personagens e fenômenos exibidos na película, como por exemplo:

Quais as características dos ambientes que podem ser deduzidas a partir do filme, tais como atmosferas, iluminação, temperaturas, agentes biológicos, fauna e flora exóticos;

Quais as habilidades e/ou dificuldades dos personagens durante o desenrolar do filme, suas epopeias, combates e atividades cotidianas que podem ser observadas;

Qual o contexto do ambiente onde vivem os personagens, veículos disponíveis, habitações, prédios utensílios diversos e suas características.

O professor neste momento pode ir anotando de forma livre no quadro os tópicos apresentados pelos grupos, instigando comentários dos outros grupos para a etapa posterior. Munidos dessa discussão preliminar podemos fomentar o debate sobre as incoerências ou possibilidades apresentadas nos filmes relacionando-os de forma qualitativa aos tópicos fundamentais da Física. Como existem muitos gêneros de filmes seria difícil estabelecer um roteiro que fosse universal, mas poderíamos começar pelo básico. Observando o que foi apontado no quadro o professor poderia iniciar questionamentos a classe, fazendo perguntas elementares e tendo um objetivo didático em mente, como por exemplo:

Pergunta: De que modo os personagens caminham?

Objetivo: A gravidade nos planetas depende da sua massa, e isso afeta o peso, então os personagens deveriam caminhar de forma diferente dependendo da gravidade a que estivessem submetidos

Pergunta: Como os personagens respiram nessa atmosfera?

Objetivo: Assim com a gravidade afeta o modo de caminhar, também afeta a densidade da atmosfera. Sabendo das dificuldades que a maioria dos seres humanos tem de respirar em altitudes um pouco elevadas, e dos limites mínimos de oxigênio presentes na atmosfera para permitir a sobrevivência, poderíamos traçar uma correlação entre a densidade, a massa dos gases presentes e a gravidade.

Pergunta: Como os personagens se comportam em relação as temperaturas?

Objetivo: A gravidade afeta a composição e concentração da atmosfera, assim, 
determina principalmente o efeito estufa, de tal forma que o planeta pode ser congelante ou uma fornalha.

Pergunta: Como são as viagens nas espaçonaves e como elas são?

Objetivo: Uma nave espacial necessita combustível para atingir uma determinada aceleração e atingir uma velocidade que permita cobrir grandes distâncias. Pode-se explorar as relações entre a massa hipotética da espaçonave e a quantidade de combustível necessário, citando exemplos como o ônibus espacial ou o projeto Apolo. Além disso, qual o alimento e a quantidade necessária para longas viagens? Como poderiam percorrer tão rápido, distâncias tão grandes?

Poderíamos elencar inúmeras perguntas ainda, mas foge ao escopo deste trabalho. O aspecto subjacente não citado até aqui é que o conhecimento prévio do filme por parte do professor não é tão relevante quanto prestar atenção na narrativa dos alunos e as cenas descritas para poder induzir e fomentar o debate. Após encerrada essa discussão, estamos prontos para introduzir o tema da "Terraformação de Marte". Esse planeta vermelho que povoa o imaginário das mentes, com vida marciana e homenzinhos verdes desde que Percival Lowell visualizou supostos "canais de irrigação" marcianos, hipótese essa nunca confirmada. Segundo alguns, devido ao instrumento que ele utilizava e as condições de observação o que ele visualizou foram os vasos sanguíneos do seu próprio olho. Objetivamente, Marte é o quarto planeta a partir do Sol, tem uma tênue atmosfera e seu diâmetro de cerca da metade da Terra. Sua massa é muito menor, cerca de $11 \%$ da massa da Terra, dente outros dados. É chamado de planeta vermelho devido ao oxido de ferro presente na superfície e que confere um aspecto vermelho alaranjado claramente visível. Nas últimas décadas surgiu um interesse maior pelo planeta pois um meteorito catalogado como ALH 81001 encontrado na Terra e que supostamente veio de Marte foi analisado e continha vestígios do que se assemelha a vida antiga. Essa notícia provocou um alvoroço nos meios científicos e muitas pesquisas e expedições tiveram início com a finalidade de estudar o planeta vermelho.

Após as discussões profícuas que nos trouxeram até aqui, podemos abordar finalmente o tema norteador deste trabalho e que nossa vivência no contexto escolar mostra que é instigador para os alunos - Terraformação de Marte. A possibilidade hipotética de que poderíamos criar em Marte as condições de vida existente na Terra e assim habitarmos esse planeta, é provocador de discussões envolvendo diferentes áreas do conhecimento, como deve ser um tema interdisciplinar. Partindo do questionamento central a ser apresentado aos alunos, "podemos terraformar Marte?" e seguindo a partir dele, podemos inferir muitos outros, que não cabe elencá-los. Dependendo do público alvo, a discussão pode ser adaptada para uma 
abordagem qualitativa com ênfase maior ou menor na parte numérica.

Podemos iniciar com a discussão das características básicas do planeta, densidade, massa, clima e o campo magnético quase inexistente quando comparado a Terra. Que implicações esses fatores teriam sobre a terraformação? Aqui podemos discutir sobre a composição da atmosfera com seus gases, a força gravitacional necessária para mantê-los ao redor do planeta, as distribuições dos gases de acordo com a sua densidade nas diversas camadas da atmosfera. A atmosfera contribui para regular a temperatura do planeta e poderiam ser estudados mecanismos tais com efeito estufa e movimentos eólicos que contribuem para distribuir nutrientes e microrganismos por vastas extensões tais com as interações conhecidas que acontecem levando poeira entre a África e América. A biosfera de Marte deveria ser reconstituída e as disciplinas de Química e Biologia, seria possível analisar maneiras de produzir condições com as quais a vida poderia desenvolver-se por conta própria. Entretanto a ausência de uma magnetosfera que age com um escudo protetor seria um problema para a vida, pois a radiação cósmica é muito nociva a vida e impede o seu pleno desenvolvimento. Poderiam ser abordadas as possibilidades teóricas de criar um campo magnético artificial que controle os processos eletrodinâmicos de uma atmosfera ionizada como forma de proteger o planeta.

Outro ponto importante é a quantidade de água necessária para o mecanismo de regulação de temperatura do planeta. Marte não possui oceanos e nem sequer possui muita água. A água dos oceanos da Terra e seu alto calor específico contribui para o equilíbrio da temperatura do planeta absorvendo calor durante o dia e impedindo-a de aquecer em demasia, ao mesmo tempo que libera esta quantidade imensa de calor durante a noite reduzindo a queda de temperatura. Dessa forma, a amplitude térmica do nosso planeta é branda e favorável a vida. Fatores como a produção de água, que podemos observar no filme Perdido em Marte, por exemplo, poderiam abrir discussões sobre a criação de ecossistemas capazes de produzir oxigênio e outros gases essenciais para a formação de uma atmosfera e, por fim, o surgimento de uma biosfera. Uma vez que a vida microscópica possa subsistir consideramos a análise de formas mais evoluídas de vida, que necessitam de um ambiente mais elaborado. A duração dos dias e a inclinação do eixo dos planetas são muito similares fornecendo dias e estações similares. Entretanto o ano marciano possui quase o dobro do ano terrestre, o que gera também estações climáticas com o dobro da duração. Como isso afetaria o ciclo das plantas mais evoluídas? Hoje sabemos que a gravidade influência direta e indiretamente o crescimento das plantas e determina muitas características, tais como a densidade do caule e o fluxo líquidos. Não sabemos como seria o crescimento de uma planta em um ambiente com 
gravidade e pressão atmosférica menor. Seria necessário um estudo elaborado para entender quais as relações entre o desenvolvimento das plantas e a duração das estações do ano e que espécies poderiam sobreviver em estações com o dobro da duração, abrindo todo um leque de possibilidades de temas geradores para a área da biologia.

Uma vez que fossem solucionados os problemas da atmosfera e do clima, da magnetosfera protetora, da vida microscópica, das plantas mais evoluídas, principalmente espécies alimentícias, restaria saber com seria a vida de animais e seres humanos. É necessário construir um ecossistema que permaneça em equilíbrio e para isso são necessárias diversas formas de vida para fechar o ciclo da vida, e que nossas necessidades sejam harmonicamente combinadas com as possibilidades oferecidas por este ambiente novo. Como seria a adaptação dos animais e da nossa vida para viajar até Marte e depois como viver lá? A viagem seria extrema, durante quase dois anos ou mais, as naves teriam que oferecer alimentos e suporte a vida até o destino. Seria como uma arca de Noé, porém em condições muito mais severas. A ausência ou redução da força gravitacional não altera apenas outras formas de vida. A pesquisa espacial moderna mostra que o homem perde cerca da $1 \%$ do cálcio dos ossos por dia devido à ausência de forças gravitacionais na estação espacial (na realidade não há ausência e sim uma resultante igual a zero, outro tema interessante para discussão tendo como pano de fundo as leis de Newton). Os astronautas que permanecem muito tempo no espaço voltam com os ossos fragilizados e recuperam-se a medida que permanecem na superfície da Terra.

$\mathrm{O}$ efeito de uma viagem por quase dois anos praticamente sem atuação de forças gravitacionais nos animas e humanos provocaria alterações na estrutura óssea dos tripulantes. E ao chegar até o destino, a gravidade no planeta Marte é cerca de $40 \%$ da gravidade terrestre, então seria necessário avaliar até que ponto a recuperação do cálcio dos ossos seria plena. Também em um planeta com pressão atmosférica e concentração de oxigênio menores seriam necessários pulmões maiores e mais eficientes para aspirar o ar e absorver o oxigênio necessário aos processos vitais. Seria necessário estudar de que forma o metabolismo dos humanos e animais seria afetado por todas essas alterações e o que provocaria, limitações ou vantagens evolucionárias. As alterações biológicas relacionadas a anos de exposição e a um campo gravitacional de menor intensidade, acarretariam mudanças fisiológicas no corpo humano, o que, até onde sabemos, tais mudanças teriam impacto direto na estatura média do ser humano, além da distribuição muscular e da densidade óssea. Um indivíduo nascido em Marte e desejasse viver na Terra também permite uma série de questionamentos. Novamente a biologia tem um largo espaço para uma série de conjecturas interessantes. 
Res., Soc. Dev. 2019; 8(9):e45891328

ISSN 2525-3409 | DOI: http://dx.doi.org/10.33448/rsd-v8i9.1328

Além desses, podemos mencionar as questões filosóficas e sociais associadas a maior duração do dia e do ano em Marte, podemos discutir a adaptação da sociedade as diferentes condições marcianas e os impactos que isso teria no seu desenvolvimento. Todos os valores considerados em nossa sociedade levam em consideração a geopolítica. Em um planeta novo com poucas espécies e surgido a partir de um único núcleo já bastante evoluído com seriam as relações sociais políticas e econômicas fornece um bom estudo de caso. Questionamentos linguísticos podem surgir a partir da discussão da modificação da cavidade bucal e órgãos fonéticos, uma vez que pressão, temperatura e composição atmosférica diferentes determinam a propagação do som, podendo-se estudar as adaptações fonéticas que ocorreriam a partir dos sons que poderiam ser emitidos com mais facilidade e com isso afeta as línguas já existentes.

Esses são exemplos de possibilidades de discussões que evidenciam que uma disciplina específica não daria conta de responder ao questionamento feito, buscando uma inter-relação entre as disciplinas, como apregoado pelo ensino interdisciplinar.

\section{Considerações Finais}

O apresentado neste texto teve por objetivo apresentar uma proposta de atividades didáticas de natureza interdisciplinar para o ensino médio, tendo como eixo norteador a utilização de um tema instigante, no caso a Terrafomação de Marte. Entretanto, o apresentado no texto limitou-se a elencar possíveis conteúdo a serem abordados e como eles estão presentes no ensino médio (disciplina, ano, tópicos). Para aplicação é necessário rever, incluir novos questionamentos e ajustá-los as necessidades da turma ou escola. Não temos a pretensão de apresentar uma proposta rígida e que não suporte mudanças, ao contrário, nossa opção por apresentar propostas didáticas situa-se na possibilidade de serem modificadas e adequadas a cada realidade educativa.

Em termos da interdisciplinaridade compactuamos com autores que destacam a necessidade de um maior detalhamento sobre como ela poderá se fazer presente nos currículos escolares, enfatizando que é preciso ter cautela ao mencioná-la, uma vez que a mesma precisa estar fundamentada em pressupostos que lhe garantam um entendimento único.

\section{Referências}

Baumert, J., Kunter, M., Blum, W., Brunner, M., Voss, T., Jordan, A., ... Tsai, Y. (2010). Teachers' mathematical knowledge, cognitive activation in the classroom, and student 
Res., Soc. Dev. 2019; 8(9):e45891328

ISSN 2525-3409 | DOI: http://dx.doi.org/10.33448/rsd-v8i9.1328

progress. American Educational Research Journal, 47(1), 133-180. https://doi.org/10.3102/0002831209345157

Carvalho Piassi, L. P. (2013). Clássicos do cinema nas aulas de Ciências-a Física em 2001: uma odisseia no espaço. Ciência \& Educação, 19(3), 517-534.

Fazenda, I. C. A (1996). Integração e Interdisciplinaridade no ensino brasileiro. 4 ed. São Paulo: Ed. Loyola.

Fazenda, I. C. A (Org) (1991). Práticas Interdisciplinares na Escola. São Paulo, Editora Cortez.

Fazenda, I. C. A. (1994). Interdisciplinaridade: história, teoria e pesquisa. Campinas: Papirus.

Hartmann, A.M., \& Zimmermann, E. (2007). O trabalho interdisciplinar no Ensino Médio: a reaproximação das "duas culturas". Revista Brasileira de Pesquisa em Educação em Ciências, 7(2), 1-16.

Japiassu, H. (1976). Interdisciplinaridade e patologia do saber. Rio de Janeiro: Imago.

Japiassu, H. (1992). A atitude interdisciplinar no sistema de ensino. Revista Tempo Brasileiro, 108, 83-94.

Mozema, E. R., \& Ostermann, F. (2016) A interdiscipl inaridade na legislação educacional, no discurso acadêmico e na prática escolar do Ensino Médio: panaceia ou falácia educacional? Caderno Brasileiro de Ensino de Física, 33(1), 92-110.

Pineau G., \& Grand J. (2002) Les histoires de vie. Que sais-je?. Paris: PUF.

Ricardo, E. (2005). Competências, interdisciplinaridade e contextualização: dos Parâmetros Curriculares Nacionais a uma compreensão para o ensino das ciências. Tese (Doutorado). Programa de Pós-Graduação em Educação Científica e Tecnológica. Universidade Federal de Santa Catarina. 
ISSN 2525-3409 | DOI: http://dx.doi.org/10.33448/rsd-v8i9.1328

Rosa, C. T. W. (2001). Laboratório didático de Física da Universidade de Passo Fundo: concepções teórico-metodológicas. (Dissertação de Mestrado). Universidade de Passo Fundo, Passo Fundo, 2001.

Rosa, C. T. W., Rosa, A. B., \& Darroz, L. M. (2014). Estudo das rampas para cadeirantes: uma proposta de tema interdisciplinar para o ensino médio. Revista Espaço Pedagógico, 21 (1), 165-177.

Stichweh, R. (2003). Differentiation of scientific disciplines: causes and consequences. Unity of knowledge in transdisciplinary research for sustainability, 1, 1-8.

Vidal, D. G. (2013). Cinema, laboratórios, ciências físicas e escola nova. Cadernos de Pesquisa, (89), 24-28.

You, H. S. (2017). Sun Why Teach science with an interdisciplinary approach: history, trends, and conceptual frameworks. Journal of Education and Learning; 6(4), 66-77.

\section{Porcentagem de contribuição de cada autor no manuscrito}

Afonso Werner da Rosa - 50\%

Alisson Cristian Giacomelli - 25\%

Álvaro Becker da Rosa - 25\% 